\title{
Phemphigus Vulgaris (Pv) in Male Patient: A Case Report
}

\author{
Reddy Mahesh Narayana*1, Gayathri $\mathrm{U}^{1}$, Neha Ramesh ${ }^{1}$ and Divya $\mathrm{G}^{2}$ \\ ${ }^{1}$ Pharm D Intern, Department of Pharmacy Practice, Sri Padmavathi School of Pharmacy, Tiruchanoor, India \\ ${ }^{2}$ Assistant Professor, Department of Pharmacy Practice, Sri Padmavathi School of Pharmacy, India
}

Submission: February 13, 2020; Published: February 21, 2020

*Corresponding author: Reddy Mahesh Narayana; Sri Padmavathi School of Pharmacy, Jawaharlal Nehru Technological University Anantapur, India

\section{Abstract}

Phemphigus vulgaris is a rare autoimmune disease is characterized by the loss of cellular adhesion due to the formation of IgG autoantibodies against desmoglein 1 or 3 . The incidence of PV occurs in ratio of 2:1(Female: Male). It mainly causes erosions and blisters of the skin and mucous membranes all over body. If not treated the disease has a high morbidity rate (5\%-10\%) in most of cases.

Keywords: Phemphigus Vulgaris; Tzanck Smear; Blistering; Desmoglein; Papules

Abbrevations: PV: Phemphigus Vulgaris, Hb: Hemoglobin, LFT: Liver Function Test, WBC: White Blood Cells, PLT: Platelets

\section{Introduction}

The term "Pemphigus" is derived from the Greek word "Pemphix" meaning bubble or blister, and vulgaris derived from Latin word (common) was originally named by Wichman in 1971 [1]. Pemphigus is a potentially life-threatening autoimmune diseases characterized by cutaneous and mucosal blistering. Pemphigus can be classified into six types: Pemphigus vulgaris, pemphigus vegetans, pemphigus erythematous, pemphigus foliaceus, paraneoplastic pemphigus, and IgA pemphigus that causes erosions and blisters of the skin and mucous membranes [2]. Phemphigus vulgaris and pemphigus' foliaceus are the two most dangerous types of phemphigus.

Pemphigus vulgaris is a rare autoimmune disease and chronic mucocutaneous disease which usually manifests first in the oral cavity in $50 \%$ of cases, which later may spread to skin or other mucous membrane, mediated by circulating autoantibodies directed against keratinocyte cell surfaces of intercellular junctions. The peak incidence of PV occurs between the fourth and sixth decades of life with a male-to-female ratio of 1:2, and it occur patients between the ages of 30 and 60 [3]. Clinically, the oral lesions are characterized by blisters that rapidly rupture and followed development of skin lesions like flaccid, easily rupture intraepithelial bullae resulting in painful erosions. While any area in the oral cavity can be involved, the soft palate, buccal mucosa, and lips are predominantly affected [2].

\section{Case Report}

A 33Years Old male patient was admitted in Dermatology Department with chief complaints of fluid filled lesiosns all over the body since7 days patient was associated with 2.5 months back , then he developed lesions all over the body which are associated with itching burning and pain, also mouth lesions present . patient initially had lesions over forehead, neck, shoulder and slowly appeared all over the body, the blisters bursted on its own within 2-7days duration the lesions showed little tendency to heal increase in size and number present . patient gives history itching and burning prior to onset of lesions, no h/o lesions over other mucosa like eyes and genitals, no h/o raw areas at trauma mone area, no f/h/o blistering disease, no palm, sole involvement, no h/o insect bite. h/o application neem juice applica 2months back that is at intial stage, no h/o photosensitivity. h/o weight loss within 2 months about $10 \mathrm{~kg}$, h/o exacerbrations on alcohol consumption . when coming to past history patient was admitted for similar complaints for 19 days and gave treatment for him includes Inj decadran 2cc IM OD, for 13 days , T. Amoxyclav 625mg TID for 7 days , Cap doxy 100mg OD for 10days, T.pantop 40mg OD, T. cetrizine 10mg OD, Cap A\&D OD, T.B complex OD, T. Calcium OD ,T. IFA OD, Mupirocin ointment F/E/A Over erosions. Patient was admitted and taken treatment in the hospital for 38days. 


\section{Muco Cutaneous Examination}

Multiple clear fluid filled lesions decreased vesicles on a clear head measuring smallest $-1 \times 1 \mathrm{~cm}$ to largest $2 \times 3 \mathrm{~cm}$ in diameter, which burst easily, multiple erosions present consecutive with crests, lesions heal with PIH, Nikolskys sign \& bulla spread sign negative.

\section{Lab Investigation}

$\mathrm{Hb}: 12.8 \mathrm{~g} / \mathrm{dl}$, Total count(WBC): 6200cumm, Differential count: P62\%, L34\%, M2 \% E2\%, PLT: 1.5L/cumm, HIV viral marker done to the patient shows negative reaction. Tzanck smear was done for the patient and it showed positive for Acantholytic cells. Biopsy was done to the patient and shows that suggestive of pemphigus foliceous. Based on the above clinical and histopathological findings patient diagnosed to Phemphigus vulgaris.

\section{Treatment}

Inj. Dexamethasone IV (1.5cc-OD)as a first line treatment for PV. As second line therapy Miconazole cream (Antifungal) apply two times a day, Clobetasol+gentamycin cream was given. Supportive therapy includes T.Hydroxyzine (25mg-OD), T. Cetirizine (Antihistamine) $5 \mathrm{mg}-\mathrm{OD}$, T.Pantoprazole (Antacid) - 40 mg OD, Cap. A\&D, T. B Complex, T. Calcium -OD, T. IFA- OD vitamin supplements, Glycerine topical application, Cap. Doxycycline -100 mg OD, Fusidic acid cream - F/L/A. On Day -15 Inj. Dexamethasone dose was reduced to $2 \mathrm{cc}$ to $1 \mathrm{cc}$ IV- OD and they continue other drugs. On Day -17 patient was experienced abdomnial pain, dark color stools, constipation and they gave drugs was Syp. Creamffin - $10 \mathrm{ml}-\mathrm{H} / \mathrm{S}$, Syp. Sucralfate - $10 \mathrm{ml}$-TID is continued to 10 days \& Cap. Doxycycline is stopped on Day-20 \& Inj. Dexamethasone - 1cc IV is stopped on Day-29 and they gave instead of Dexamethasone they given T. Prednisolone - 20mg OD is continued up to Day-30 and Day-31 dose of Prednisolone was reduced to $20 \mathrm{mg}$ to $10 \mathrm{mg}$ OD is continued up to Day- 38 then stopped. On Day-39 again Inj. Dexamethasone IV (1CC OD), T. Augmentin (Antibiotic) $625 \mathrm{mg}$ BD is given to the patient, on Day-46 T. Augmentin was stopped and same therapy is continued up to Day-52 and after patient is discharged against medical advice (Figures $1 \& 2$ ).

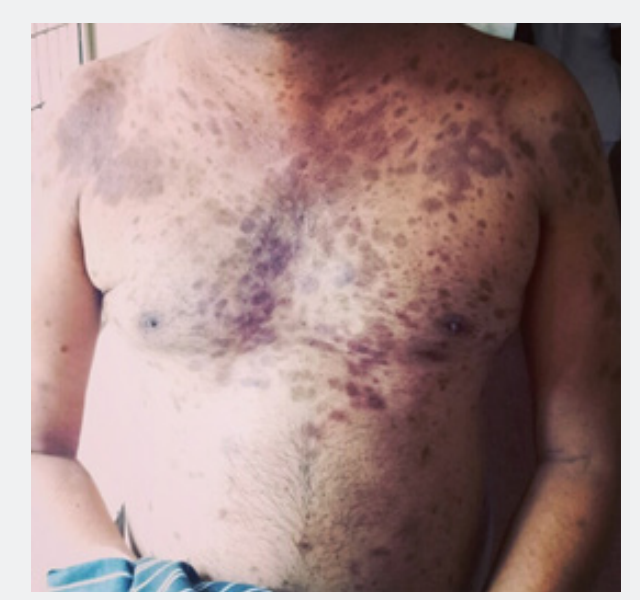

Figure1: Widespread of erosions, and crusts of phemphigus vulgaris.

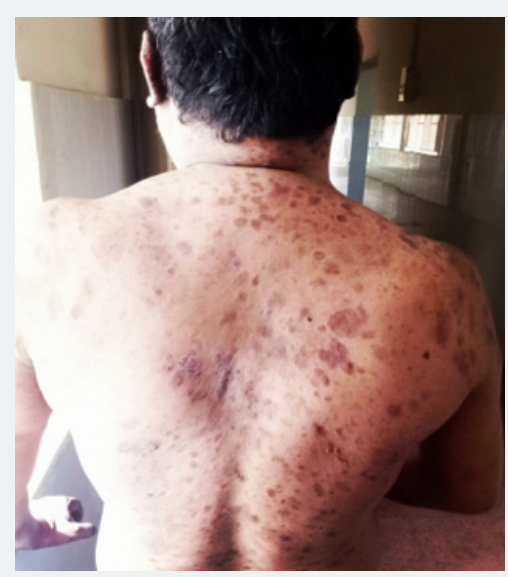

Figure 2: Erythematous macules, papules, vesicles all over the body. 


\section{Discussion}

Phemphigus vulgaris is a rare autoimmune with intraepidermal bullous lesions which affect in specific oral, genital or ocular mucosa and the epidermis, other mucous membrane is includes nasal mucosa, larynx, and esophagus. Increased salivation and problems with chewing and swallowing are the main subjective complaints [4]. This disease is characterized by the loss of cellular adhesion due to the formation of IgG autoantibodies against desmoglein 1 or 3 . Types 1 and 3 desmogleins are found within skin whereas mucosa contains only the type 3 variant. The severity and site of the disease will depend on whether types 1 and 3 desmogleins are affected $[1,2]$. The function of desmoglein 1 is preserved preventing the development of skin lesions. Loss of cell to cell adhesion results in the development of intraepithelial blisters that rupture following minimal trauma, sloughing eroded areas of skin $[3,5]$.

The etiology of PV is still unknown. The phemphigus group diseases are characterized by the production of autoantibodies against intercellular substances and, therefore, classified as autoimmune diseases. The presence of a viral infection may also be involved in autoantibody production. Strong associations with certain HLA Class II alleles have been demonstrated in PV $[2,4]$ Other initiating factors reported include certain foods (garlic), infections, neoplasms and drugs. The drugs commonly presented in the thiol group such as Captopril, Penicillamine and rifampicin [4]. The basic therapy consists of local or systemic corticosteroid therapy. Adjuvant therapies includes dapsone, cyclosporine, methotrexate, mycophenolate mofetil cyclophosphamide and azathioprine are mostly preferred in PV [6]. Other drugs such as thalidomide, colchicine, antibiotics and retinoids have also been used in mild to moderate condition [7]. Traditional drugs includes antioxidants, calcium and vitamin supplements are also provided, antiseptics mouth washes should be given to improve local oral hygiene $[6,8]$.

This patient was treated with Inj. Dexamethasone IV(1cc/2cc), T. Dapsone (40mg), T. Prednisolone (10 mg/ 20mg), T. Fluconazole(150mg), T. Pantoprazole (40mg) specific therapy for PV. The patient has hyper pigmentation lesions all over body does not cure completely then patient is discharged on Day- 52 against medical advice.

\section{Conclusion}

Pemphigus vulgaris is a rare cause of chronic ulcerationof oral mucosa, hyperpigmentation all over the body. Dental professionals must be familiar with clinical manifestation of PV. If not treated promptly, the disease has a high morbidity rate $(5 \%-10 \%)$ in most of cases [1].

\section{Acknowledgement}

I would like to thank my parents and friends who have helped me with their valuable suggestions and guidance has been helpful in various phases the completion of the project.

\section{Conflict of Interest}

The author declares there is no conflict of interest.

\section{References}

1. Ishitha Banerjee, BiyasBhowmik, Anirban Maji, RupamSinha (2018) Pemphigus vulgaris - A report of three cases and review of literature. Journal of Family Medicine and Primary Care 7(5): 1109-1112.

2. SandhyaTamgadge, AvinashTamgadge, Daivat M Bhatt, SudhirBhalera, Treville P (2011) Treville Pereira.Pemphigus vulgaris. Contemporary Clinical Dentistry 2(2): 134-137.

3. RaiArpita, Arora Monica, NaikmasurVenkatesh, SatturAtul, Malhotra Varun (2015) Oral Pemphigus Vulgaris: Case Report. Ethiopian Journal of Health Sciences 24(4): 367-372.

4. Bandaru Nagaraju, Anne Ramu, Suryadevaravidhyadhara (2016) A Case Study on Pemphigus Vulgaris Indian Journal of Pharmacy Practic 9(4): 266-268.

5. Mitsuhiro Ohta, Seiko Osawa, Hiroyasu Endo, Kayo Kuyama, Yama Moto, et al. (2011) Pemphigus Vulgaris Confined to the Gingiva: A Case Report. International Journal of Dentistry 2011: 207153.

6. AsifaNiyaz, B K Viswanath (2019) A typical presentation of pemphigus vulgaris - A rare case report. Our Dermatology Online 10(1): 88-90.

7. Nadia Ben Lagha, Vincent Poulesquen, Jean Claude Roujeau, Alp Alantar, Louis Maman (2005) Pemphigus Vulgaris: A Case-Based Update. Journal of the Canadian Dental Association 71(9): 667-672.

8. Hari Babu Ramineni, ManasaYerraguntla, SaranyaPulimila, Narendra B, Vidhyadhara (2015) Pemphigus vulgaris: a rare case report. International Journal of Research in Medical Sciences 3(6): 15431544. 
This work is licensed under Creative Commons Attribution 4.0 License DOI: 10.19080/JOJDC.2020.02.555587
Your next submission with Juniper Publishers will reach you the below assets

- Quality Editorial service

- Swift Peer Review

- Reprints availability

- E-prints Service

- Manuscript Podcast for convenient understanding

- Global attainment for your research

- Manuscript accessibility in different formats

( Pdf, E-pub, Full Text, Audio)

- Unceasing customer service

Track the below URL for one-step submission https://juniperpublishers.com/online-submission.php 